\title{
Discussion on College Practice Education Model -- Taking College Practice Education Model in Chongqing City
}

\author{
Haitao Lan \\ Chongqing Vocational Institute of Engineering, Chongqing, 400037, China
}

Keywords: Colleges, Practical activities, Education model, Exploration

\begin{abstract}
Colleges enhance the practice of educating people; focus on innovative training model, which is both important breakthroughs for creative talent mode and it is also a major issue to explore in university education model. In recent years, colleges and universities in Chongqing practice of educating people to explore aspects of the powerful, and promote innovative training model, and received good results.
\end{abstract}

\section{Introduction}

Social practice of college students education, increase their abilities, their talent and dedication effective way society, colleges and universities to new ideas, new culture, new technology "Fountainhead." In the spirit of the times innovation has become the core of the new situation, and actively promote innovative research students 'social practice, not only in favor of education in schools, it is an important way to college students' growth.

\section{Implementation approach of Chongqing's college practice education}

\section{Policy guidance}

The issue on further strengthening and improving ideological and political education from CPC Central Committee and State Council points out that "Social practice is an important part of the ideological and political education for the promotion of college students understand the society, understand the country and increase their abilities, contributing to society, exercise perseverance, cultivate character, enhance social responsibility has an irreplaceable role." In the guidance of national macro education policy under Chongqing based on local realities, municipal government and education authorities have issued a CPC Chongqing municipal government on the good social practice of college students notice, Chongqing Social practice of college students work plan and so on a series of policy documents. It introduced a series of documents, leading the students, schools, social institutions, government agencies to actively participate in social practice of systems engineering college students, within the city set off a vigorous climax Students' Social Practice.

\section{Specific implementation}

Chongqing municipal universities in accordance with the requirements of the relevant documents and under the guidance of Chongqing Municipal Education Commission, the relevant functional departments, summer vacations organized and orderly school where students participate in various forms of social practice, such as the study and practice, innovation and entrepreneurship, military training, paid internships, work-study program, volunteer services, social surveys and "countryside", "four into the community" and other state of practice; and broad participation in the daily activities of the campus culture, science and technology innovation and other diverse practice education activities. 
Colleges and universities in the form of organized each category during practice education activities strive to see the effect of the results.

\section{Summarize and report}

In order to colleges continue to improve the quality of education practice and explore a maturing practice ways of educating people, Chongqing City Education Committee asked universities to link the summary report as an integral part of the practice of educating people to work good job. In the selection of the city's outstanding units be centralized reporting of recognition, to encourage the advanced, exchange of successful experiences, spur lagging behind, in order to promote the city's practice of education quality.

\section{Characteristics of Chongqing's college practice education}

\section{Complete the contents and system of practice education}

Teaching, military training, social practice is the practice of educating people in the main form. Advocacy and support in the Chongqing party and government organs, enterprises and institutions, the practice of educating College of Chongqing people work real economic and social development, innovation launched Co-op, the founder of micro-enterprises, rural, community and government agencies experiential social practice other activities to further enrich the content of the practice of educating people, educating people in the form of practical innovation. Chongqing Education College practice formed a working party committees at all levels of importance, government support, leading colleges and universities, educating people practice a new pattern of social participation.

\section{Highlight key points of practical education}

Practical education is a systematic project, different times and different personnel training objectives, the focus should be different. Students in the social practice organization, the major colleges and universities in Chongqing training objectives according to the school's own position and school characteristics, and school personnel to establish, in accordance with the principles focused, integration of resources, carefully refined the practice of educating people work program, in the program focus on enhancing the practice of educating people targeted and effective, clear the corresponding working bodies and workforce.

\section{Further enhance practice teaching section}

Practice teaching is an important part of the school teaching work, is an important part of deepening the classroom teaching, the students get to master an important way of knowledge, personnel training system is currently the weakest, and we must strengthen the link. In practice, educational work, the major colleges and universities in Chongqing strong advocate of social practice, combined with professional features and personnel training requirements, classification standards and the development of practice teaching students practical credit requirements, increasing the proportion of practice teaching, the students participate in social practice activities into educational practice part of the overall consideration, to ensure that the requirements of hours, and included credits.

\section{Promote innovation entrepreneurial practice}

Innovation and entrepreneurship education is a specific requirement creative spirit and creative ability, is an important channel for personnel training. Chongqing municipal government agencies, educational authorities attach great importance to innovation and entrepreneurship students education, Chongqing major universities and local governments combined with the actual situation in the university town, schools and other institutions of higher learning established innovation and entrepreneurship practice base, the introduction of incentives, arrangements business mentor personalized business guidance, to attract college students venture into the base. Universities also offer the appropriate courses, to carry out innovation and entrepreneurship education, innovation and 
entrepreneurship students' awareness, guide students to actively carry out innovation and entrepreneurship.

\section{Organize students co-op program}

Students use the organization to carry out paid internships winter and summer activities, it is another initiative in University education practice work. Annual summer and winter holidays, Chongqing government agencies, large enterprises and institutions have to provide some internship so that students participate in practice, these students to party and government organs, enterprises and institutions to participate in internships practice, the employer must pay the amount of salary to students. Students participate in paid internships, both allow students to integrate into the community to participate in practice, work and life experience, but also get some income paid to carry out this event, won the Chongqing University Students, unanimously endorsed by parents and the community.

\section{Volunteer service and social research activities}

Students in the organization to carry out cultural, science and technology, health "officials" science and education, sports, law, health "four into the community" volunteer service activities, colleges and universities in Chongqing focus to guide students to apply the knowledge and skills to serve the people, contributing to society, emotional values and culture of serving the people, promote socialist morality. At the same time, to encourage the community of college students to carry out extensive research and write a research report society, actively reflect public opinion and the students hear and feel. Major colleges and universities to carry out social research report yearly contest, the valuable research report presented to the major party and government organs, social organizations, decision-making reference for the establishment of students and government organs, social groups of society and public opinion, "overpass."

\section{Chongqing's college practice education activities show good educating effect}

\section{Promote students' transformation from theoretical knowledge to practical skills}

College students are relative simplicity and closed society, which for college students to stay in school and cultural knowledge is advantageous, but with the development of the information age society for college students to obtain knowledge of the source of great change, to adapt to the rapid development of society, closed institutions of higher learning will inevitably lead nurturing students from the community, the social reality lack of understanding, lack of social identity, social integration to the students bring a lot of difficulties and difficult to adapt. It is to see this, Chongqing major universities and carry out content-rich, diverse forms of practical educational work, so that students in practical activities, subtly strengthen the socialist core values, identity, theoretical knowledge learned in books into to the real world to practice, through proven and enrichment, form their own value judgments. Interviewed students in the interview process generally reflected by social practice learned society, cultivate self-reliance, good quality, and social life of self-ability to adapt to experience productive labor, to understand the situation, social situation, the people, the students in practice get real experience, education and inspired by the sublimation of thought, social responsibility and mission to be strengthened.

\section{Promote students' transformation from knowing to unity of moral knowledge and practice}

Theoretical knowledge university classroom learning does not represent the actual work skills, in real life, although many university graduates have higher education, but it does not work well into the role, you cannot complete the task well, a lot of organs, enterprises to participate in the work of the students just called "not weaned child." This is because the theory of knowledge cannot represent the practical skills; a lot of theories cannot be directly applied to real life. Many problems, one aspect of 
knowledge alone is difficult to solve, need to consider many factors, the integrated use of a wide range of knowledge and skills to resolve. The social practice is the best ways to temper students apply what they learn. Students in social practice through 'problem to solve the problem; new problems to solve new problems, "the cycle process, college students sense of responsibility, sense of innovation, teamwork, ability and interpersonal and coordination has been greatly and enhance the level of training, the actual ability to work in social practice to explore, experience, insights and summarize gradually increased.

\section{Promote the improvement of college students' overall quality}

The overall quality of a person is not born, but trained acquired through continuous training. Students participate in social practice is an important way to improve students' quality education, with the moral, aesthetic, intellectual, and many other educational content. Improve the overall quality of a person need to get in practice. Social practice out of the university classroom teaching has the dual attributes of social education and school education, but also to deepen the classroom teaching is the practice of theoretical knowledge. Chongqing organization Students study and practice, innovation and entrepreneurship, military training, paid internships, work-study program, volunteer services, social surveys and "countryside", "four into the community" and other practical activities, on the one hand to enable students to get a lot in practice new life experience, cultivate perseverance and determination, is a self-education, self-discipline, self-motivation process; on the other hand, the students participate in social practice is a rare post job role experience, which will help students to establish a correct career morality and labor discipline. Many students participate in social practice, said after social practice, his body had a sense of the kind of time, organization and discipline is not strong disadvantage is undergoing great changes.

\section{Expand students' vision}

Social practice of college student's ideological and political education for the community to be an important way to the reality of ideological and political education, colleges and universities is an inevitable extension of classroom education and useful supplement. Social practice of college students in Chongqing organize, organize students in-depth mining industry grassroots rural fields, in-depth frontline neighborhoods and communities, applying the right ideas and theories in practice to guide their behavior, so that students on the ground to complete a comprehensive life experience. Students practice at the same time, the scientific understanding and objective view of social development issues, a profound observation and study all walks of life attitude, professional skills and life style, to deepen the workers and peasants, the people's awareness and understanding of the community, so students learn verified in practice of ideological and political theory courses are scientific and correct.

\section{Innovation value of practice education work in Chongqing's colleges}

\section{Innovation of the students' social practice system}

Practice carried out in University of educating people, it is a university student social practice and vocational skills training and effective aspects of development, learning and College Students combine theory and practice of effective form. Students' social practice in this work, from the organization point of view, a simple change in the past by the school, student organizations involved in the situation, but the local party committees and governments at all levels to mobilize from the policy, institutional level, enterprises and institutions to participate, formed a unique social practice of college students a new system, a variety of resources to get the maximum integration and synergies; from a practical point of view the content of university students in Chongqing social practice, significantly enriched content, including the Social Practical content Students study and practice, innovation business, military training, paid internships, work-study program, volunteer services, 
social surveys and "countryside", "four into the community" and other practical content. Students' Social Practice Chongqing innovative new systems of social practice students, cracked the many problems facing the social practice, and promote the development of new educational work in higher educational institutions.

\section{Discover new resources for students' social practice}

For a long time, since the system is not enough to guide the policy level, university education practice work is often hampered by a lack of resource constraints, in this activity, a lot of enterprises, institutions, government agencies are not keen to participate, resulting in higher educational work a mere formality, even if there is a formality that cannot be resolved through social practice students taught to achieve beneficial purposes. Some colleges and universities in organizing social practice process, due to the constraints and lack of motivation of various factors in the organization and form appear single, leading to the theory and teaching out of line, showing the students to participate in the degree of social practice is not high, limited coverage, continued poor and so on. The practice of educational work carried out by colleges and universities in Chongqing, policy and institutional guaranteed, at all levels of party and government organs, enterprises and universities organize a common understanding, give full play to their own resources effectively and achieve combination of resources the greatest degree of social practice, as the smooth development of the practical education work has laid a solid resource base.

\section{Acknowledgments}

This article is one of 2013 Chongqing Education Committee humanities \& social sciences projects(13SKT11).

\section{References}

[1] Hu Shuxiang, Wu Manyi: Students Social Practice Education Theory and Methods, Beijing people's publishing house, page 2010.1.

[2] Feng Ai, Fan Bing: Introduction to college students' social practice. Beijing: Social Sciences Academic Press, 2005.

[3] He Wanguo, Qi Xingui. The formation and the training mechanism of college students' practice ability. Higher education study, 2009.62-66.

[4] Cao Xianrong, On innovation of students social practice. Education theory and practice, 2010.13-15

[5] CPC Chongqing Municipal Committee and Chongqing Municipal People's Government Notice on the social practice of college students. Chongqing No. 27 [2010].

[6] Notice of issuing College students' social practice work practices in the city from CPC Chongqing Municipal Committee and Chongqing Municipal government office. Chongqing No.54 [2010]. 